\title{
ANALYSIS OF INDOOR ENVIRONMENT IN CLASSROOM BASED ON HYGIENIC REQUIREMENTS
}

Miroslav JAVORČEK ${ }^{1 *}$, Zuzana STERNOVÁ ${ }^{2}$

\section{Abstract}

The article contains the analysis of experimental ventilation measurement in selected classrooms of the Elementary School Strba. Mathematical model of selected classroom was prepared according to in-situ measurements and air exchange was calculated. Interior air temperature and quality influences the students' comfort. Evaluated data were compared to requirements of standard (STN EN 15251,2008) applicable to classroom indoor environment during lectures, highlighting the difference between required ambiance quality and actually measured values. $\mathrm{CO} 2$ concentration refers to one of the parameters indicating indoor environment quality.

\section{INTRODUCTION}

Experimental measurements were held at the Elementary School (ZŠ) Strba in two stages. The preparation stage dated in December 2012 was focused on observation and behavior of students during classes, and on their habits. Measurement outcomes and results were analyzed and represented the basis for main measurement.

Main experimental measurement in-situ was held during Dec $10-16,2013$ in order to analyze the conditions and parameters within the whole week. It was necessary to obtain all data affecting the quality of indoor environment during the entire measurement. All reviewed indoor environment quality parameters covered the time during classes, afterwards and when nobody was present in the building premises.

Indoor environment quality was measured in the $2 \mathrm{nd}$, 5th and 8th grade classrooms, as well as in the joint communication corridor where the classrooms were accessed from, each through the only door located in the wall opposite to the windows. The classrooms clearance refers to $3,400 \mathrm{~mm}$ and volume refers to $178.5 \mathrm{~m}^{3}$.

\section{AIR INFILTRATION}

Air is infiltrated in the building as a result of pressure difference caused by gravitational force and wind effect, and further from the building through the facade construction untight areas or open pores of

\section{Address}

1 Faculty of Civil Engineering, Slovak University of Technology, Radlinského 11, 81005 Bratislava, Slovakia

2 Building Testing and Research Intitute, Studená 3, 821 04, Bratislava, Slovakia

* Corresponding author: miroslav.javorcek@gmail.com

\section{Key words}

- Natural ventilation,

- Air exchange,

- Indoor environment

- Elementary school buildings.

the used building materials. Such uncontrolled air flowing and resulting air exchange can be considered the way of natural ventilation (STN EN 15242, 2007).

$$
V_{\mathrm{inf}, \mathrm{i}}=2 \cdot V_{\mathrm{i}} \cdot n_{50} \cdot e_{\mathrm{i}} \cdot \varepsilon_{\mathrm{i}}
$$

$n_{50}$ air exchange intensity per an hour $(1 / \mathrm{h})$ reported at atmospheric pressure difference $50 \mathrm{~Pa}$ between the building interior and exterior, including the influence of the openings,

$e_{\mathrm{i}}$ building wind protection factor,

$\varepsilon_{\mathrm{i}}$ elevation correction factor: relation of wind speed increase to vertical distance of the building (height) from the ground level.

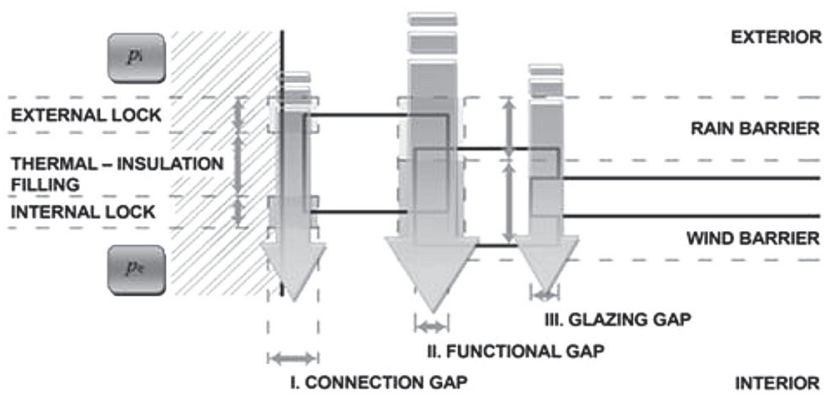

Fig. 1 Air infiltration through the opening/gap structure. 

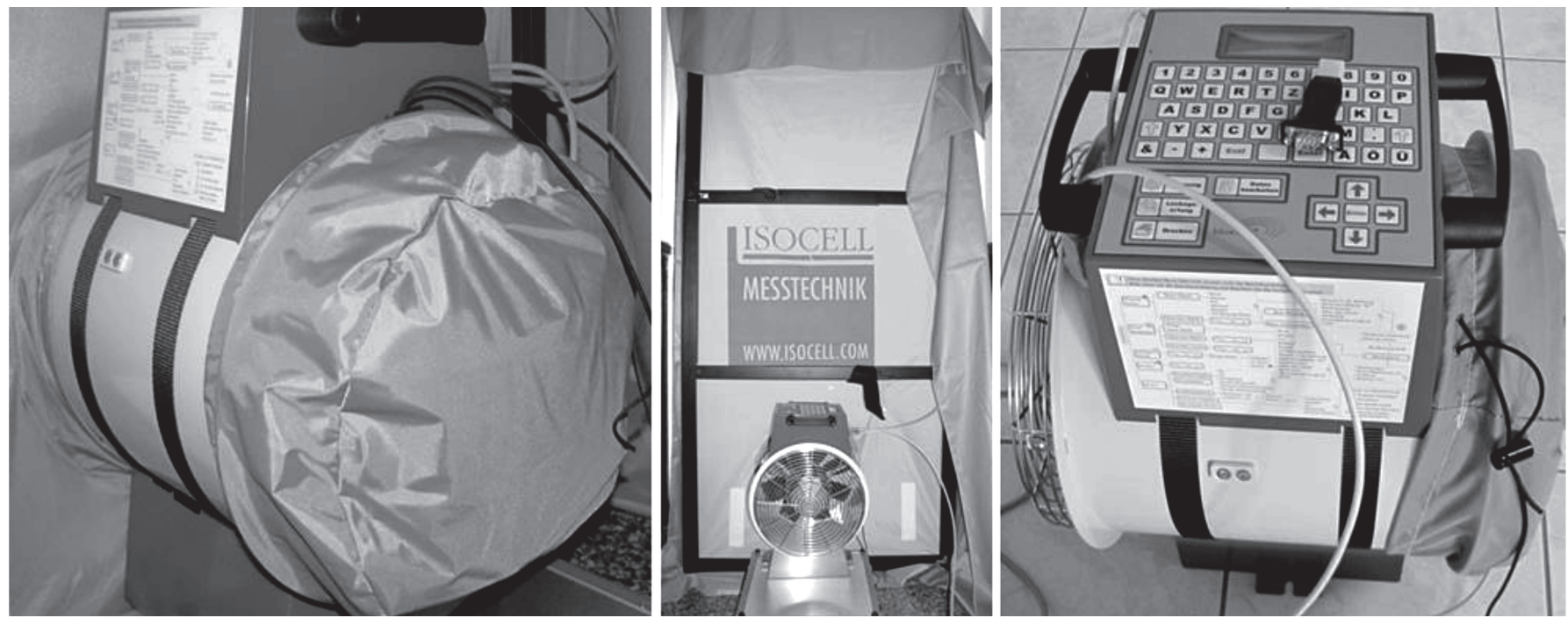

Fig. 2 Air permeability measurement at ZŠ Štrba with ventilator (Javorček, M., 2016).

So called Blower door test or determination of classroom air permeability pursuant to (STN EN 13829, 2001) allows for specification of one of the parameters entering the numerical simulation program EnergyPlus (EnergyPlus simulation program). The measurements were made repeatedly in all reviewed classrooms in order to reduce the risk of a single measurement incorrectness.

Air permeability was measured in all analyzed classrooms on the same day. Measurements pursuant to (STN EN 13829, 2001) were repeated in order to eliminate the occurrence of a single measurement error. Measurement results from all analyzed classrooms were almost equal. Air permeability value considered during the simulation referred to $\mathrm{n}=1.5 \mathrm{1} / \mathrm{h}$.

Tab. 1 Air permeability measurement result pursuant to STN EN 13829 (Javorček, M., 2016).

\begin{tabular}{|c|c|c|c|}
\hline Classroom & $\begin{array}{c}\text { Measurement I. } \\
n_{50}=1 / \mathrm{h}\end{array}$ & $\begin{array}{c}\text { Measurement II. } \\
n_{50}=1 / \mathrm{h}\end{array}$ & $\begin{array}{c}\text { Result value } \\
n_{50}=1 / \mathrm{h}\end{array}$ \\
\hline 2. & 1.52 & 1.50 & 1.51 \\
\hline 5. & 1.49 & 1.52 & 1.50 \\
\hline 8. & 1.50 & 1.53 & 1.51 \\
\hline
\end{tabular}

\section{CLASSROOM INDOOR ENVIRONMENT}

$\mathrm{CO}_{2}$ concentration in classroom is a dynamic parameter. It changes with time in case of empty classroom but much more when the classroom is full of students. $\mathrm{CO}_{2}$ concentration in exterior atmosphere reached average value $380 \mathrm{ppm}$ within entire period of experimental measurement. Such value wasn't reached in the classrooms either during classes when the windows were opened or when the school was empty, and air exchange was ensured through infiltration and exfiltration. Concentration started rising with students coming in the classroom, usually after 07:20 a.m. It is impossible to specify either the increase rate and $\mathrm{CO}_{2}$ concentration drop, or their development. As we can see on the graphs, air temperature curve and $\mathrm{CO}_{2}$ concentration in the classrooms are similar in case of significant and sudden changes. This similarity is influenced by the number of opened windows in a classroom. The classrooms of the 2nd, 5th and 8th grade of ZŠ were subject to the analysis.

Relation cannot be determined unambiguously from total air temperature and $\mathrm{CO}_{2}$ concentration development in the classrooms, but it is possible to monitor mutual drop of both parameters in selected analyzed sections. This effect occurs during selected breaks in the classes when the classrooms are emptied and air exchange rate in a classroom is sufficient enough to ensure much higher concentration drop.
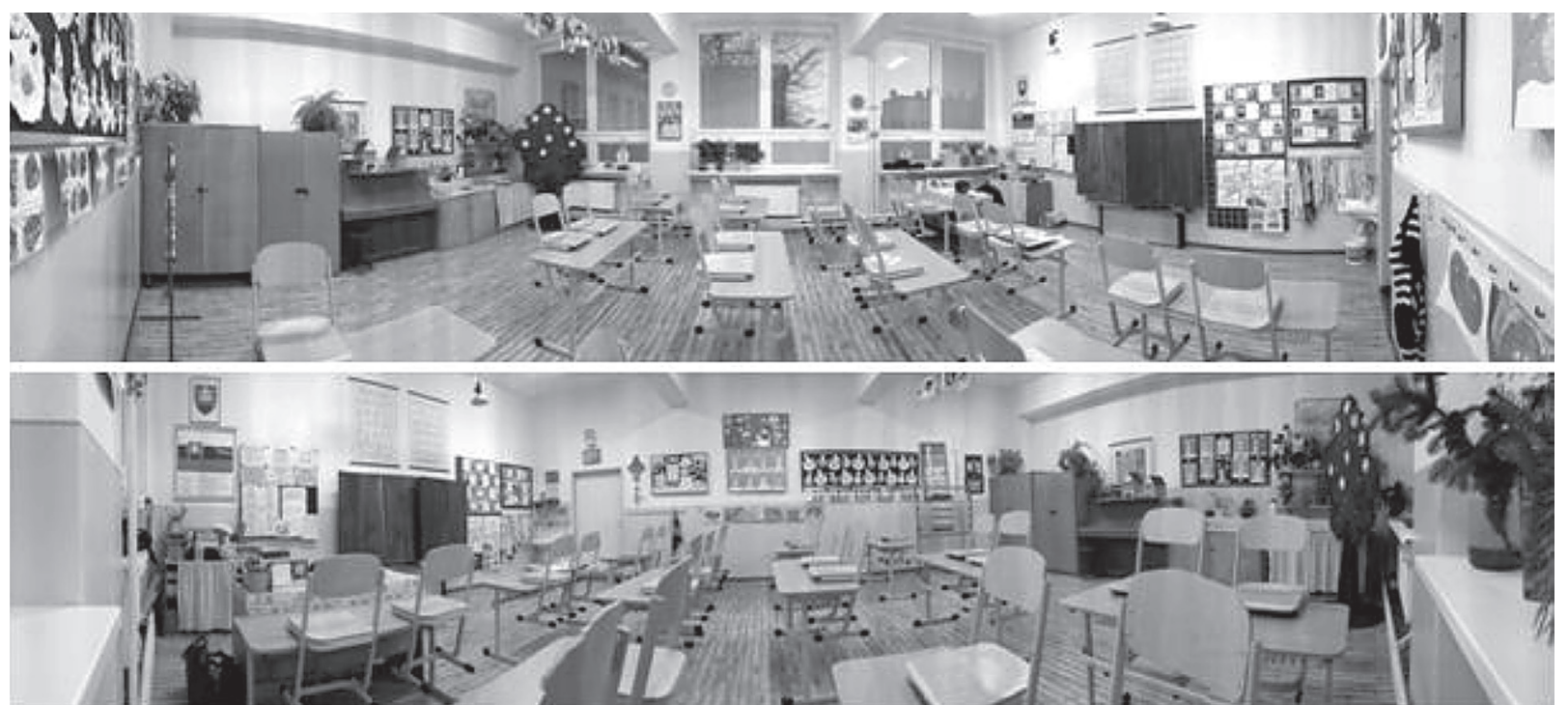

Fig. 3 Panoramic photos of the 2nd grade classroom (Javorček, M., 2016). 


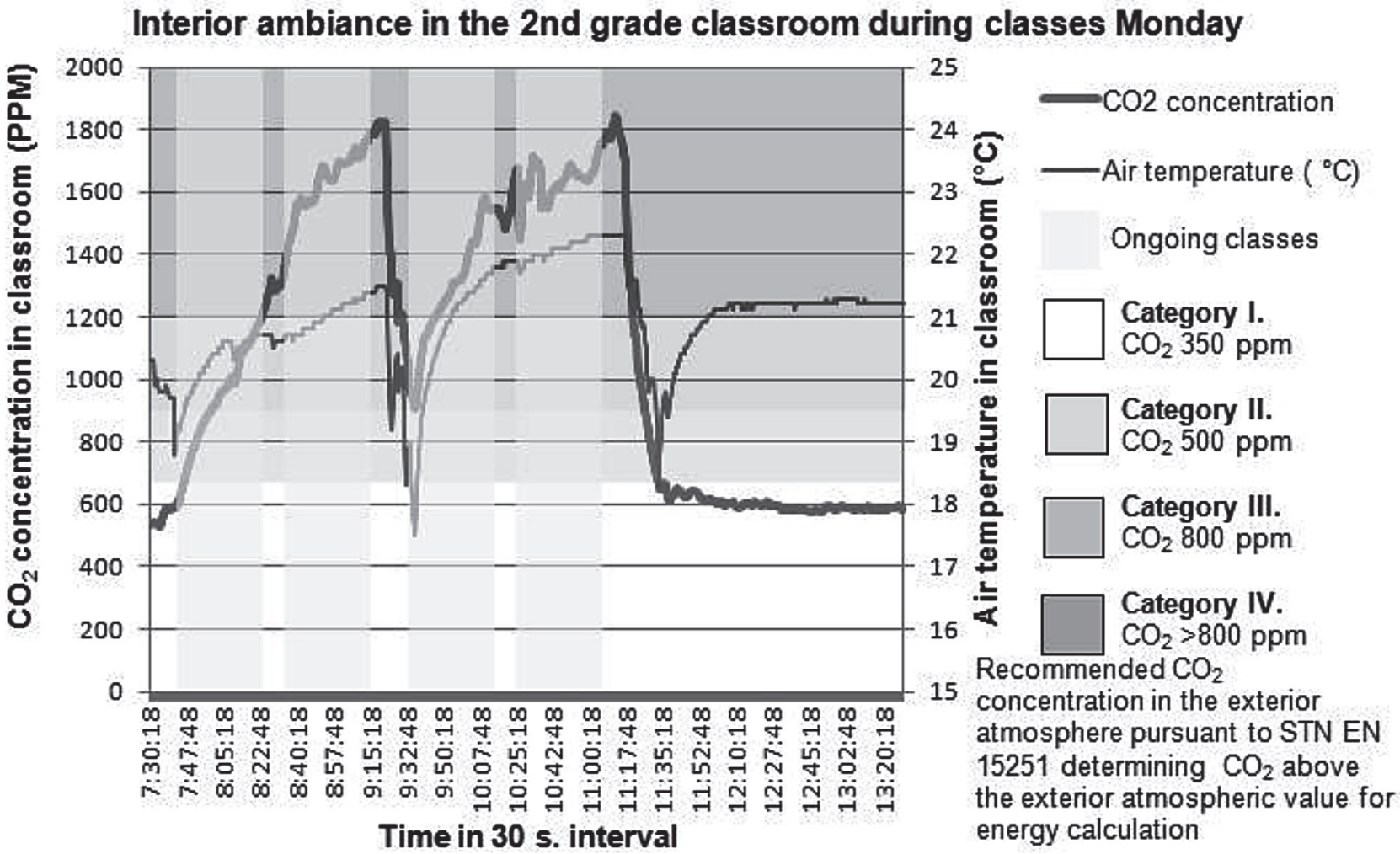

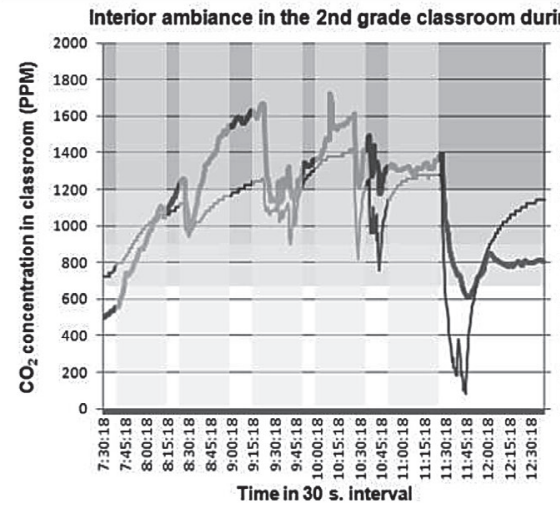
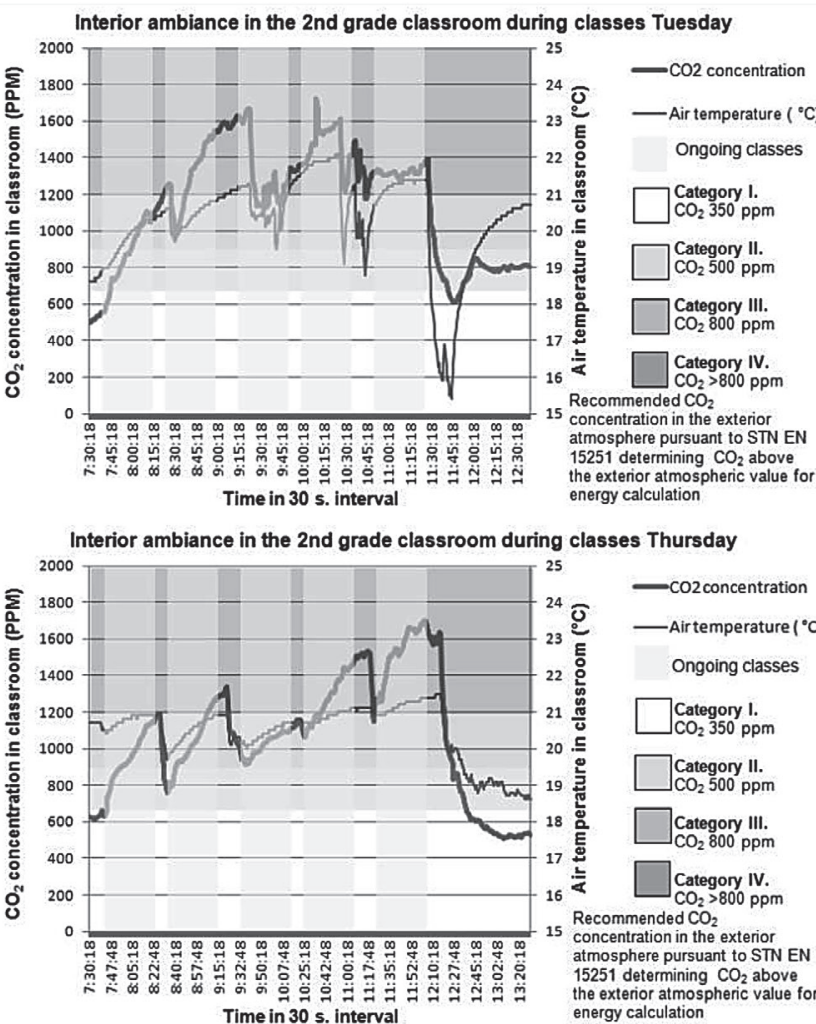
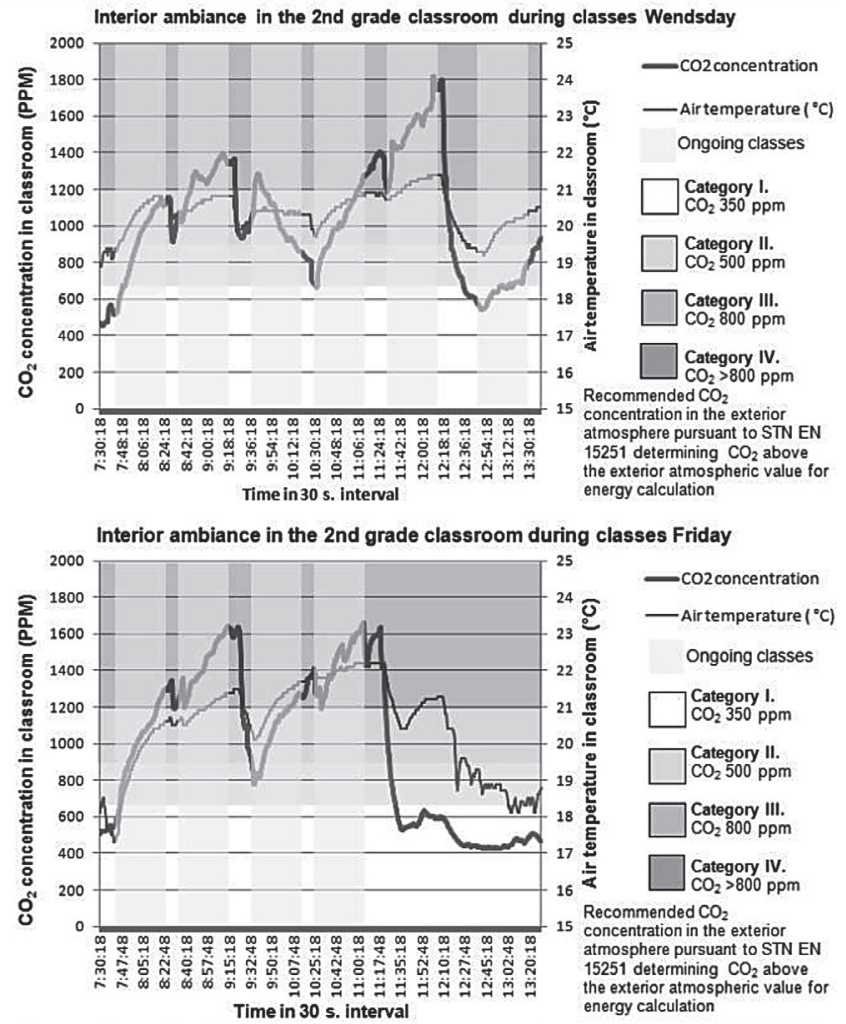

Fig. 4 Graphs of $\mathrm{CO}_{2}$ concentration and air temperature in the 2nd grade classroom during classes (Javorček, M., 2016).

Gradual $\mathrm{CO}_{2}$ concentration drop has been observed at the time of empty classrooms, caused by air ex- and infiltration. Mean $\mathrm{CO}_{2}$ concentration upon turnout of the first students of the 2 nd grade in the classroom refers to $525 \mathrm{ppm}$. This mean value is by $145 \mathrm{ppm}$ higher than the mean $\mathrm{CO}_{2}$ concentration in the exterior atmosphere during entire experiment. Accordingly, we can point out to the fact that air infiltration itself cannot ensure ventilation of classrooms corresponding to exterior $\mathrm{CO}_{2}$ concentration. This finding has been confirmed by the weekly measurement results with apparent increase trend on each following day within the week. 


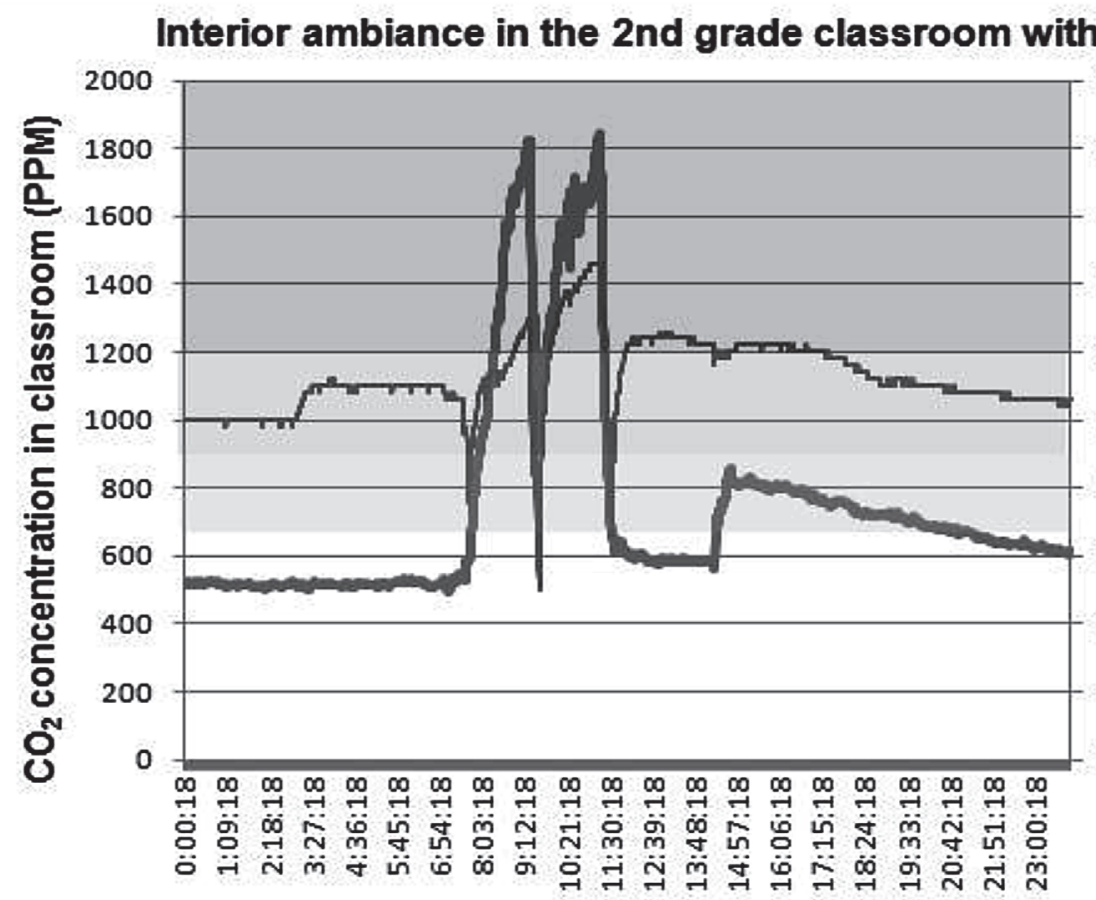

Time in $30 \mathrm{~s}$. interval

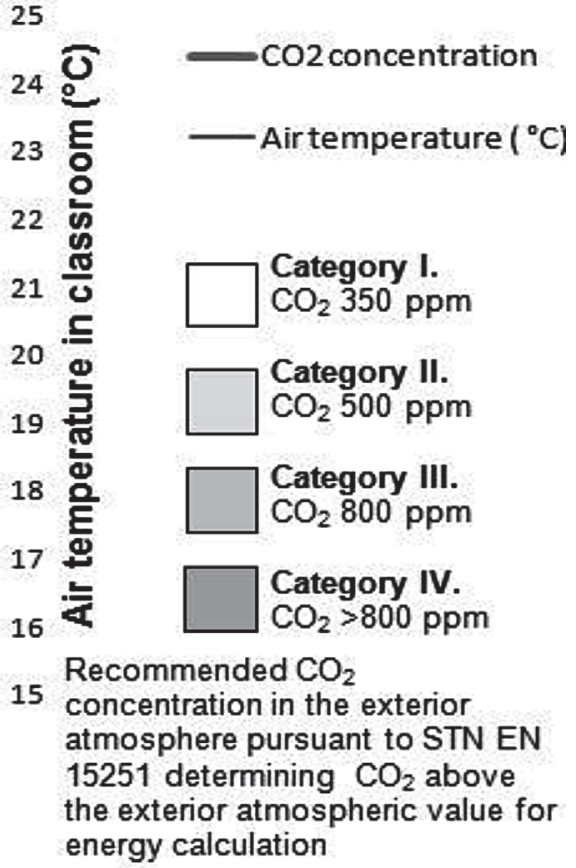

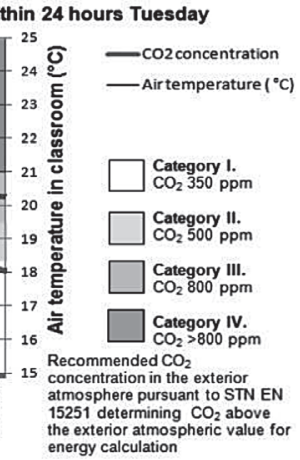

24 hours
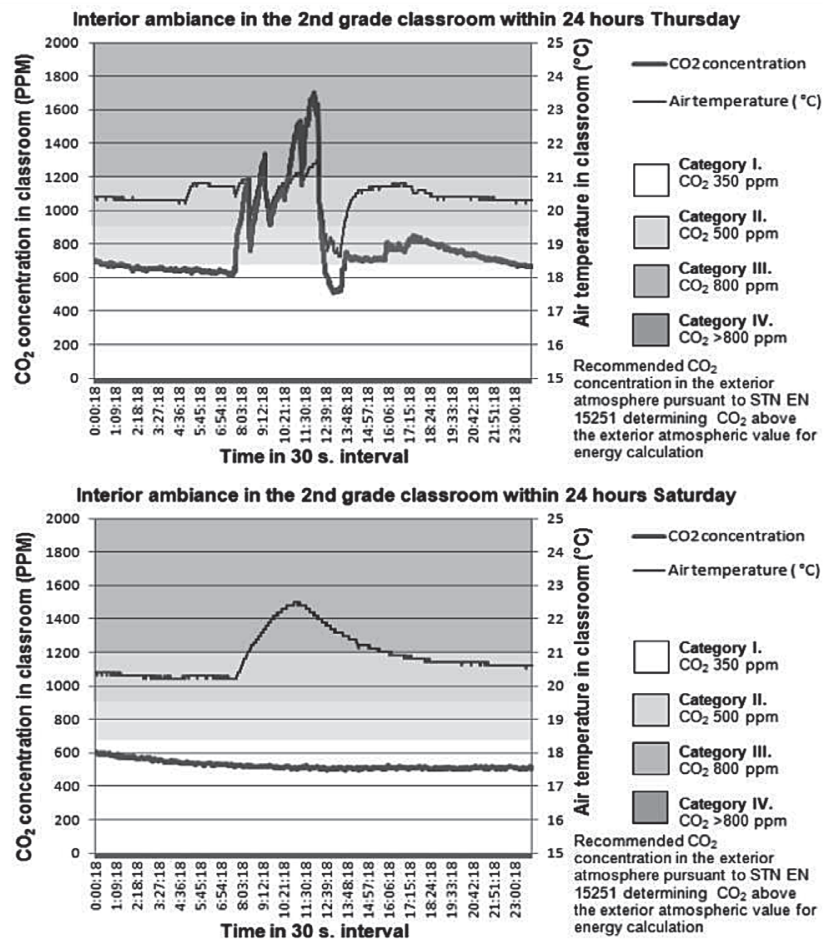
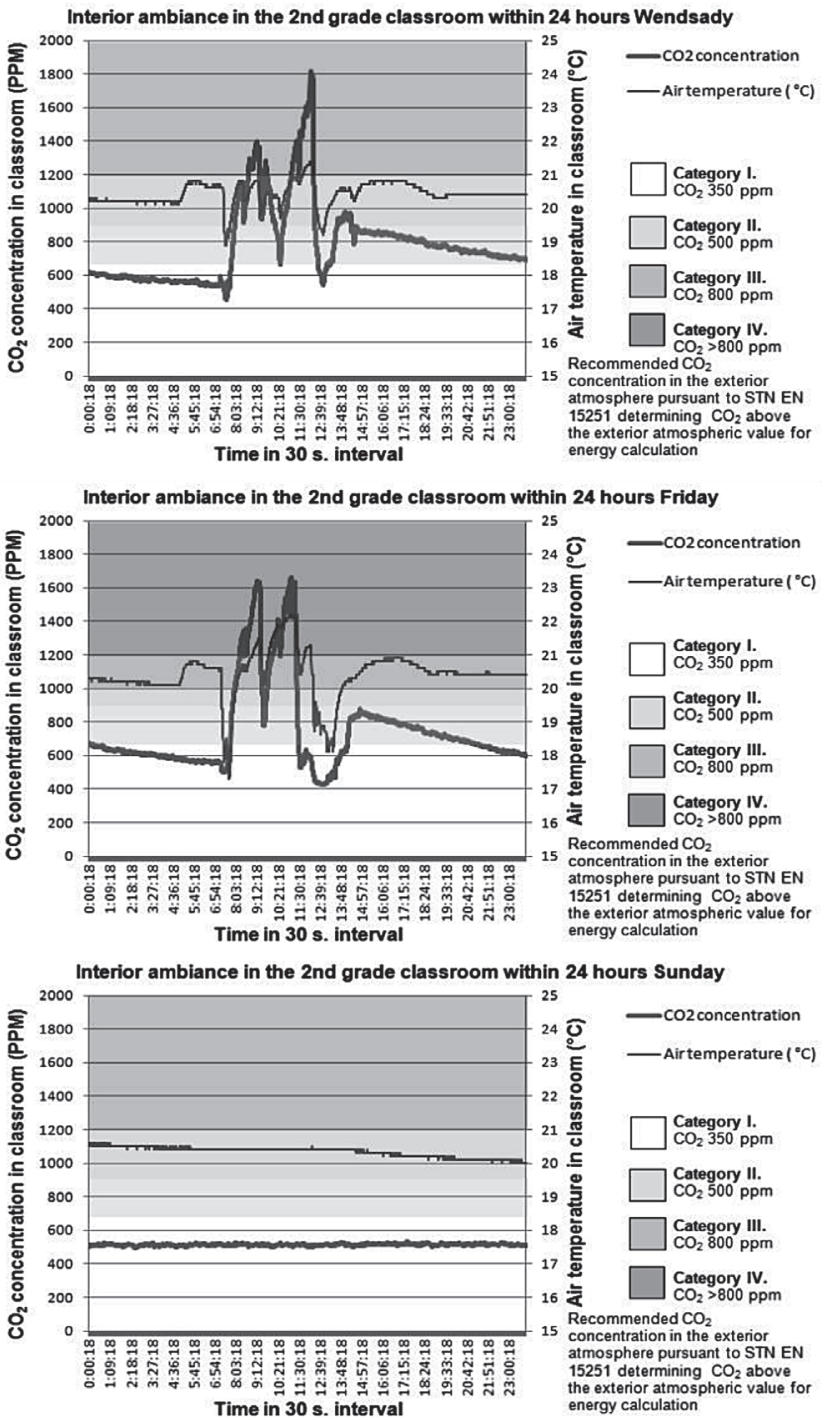

Fig. 5 Graphs of $\mathrm{CO}_{2}$ concentration and air temperature in the 2nd grade classroom during seven days (Javorček, M., 2016). 


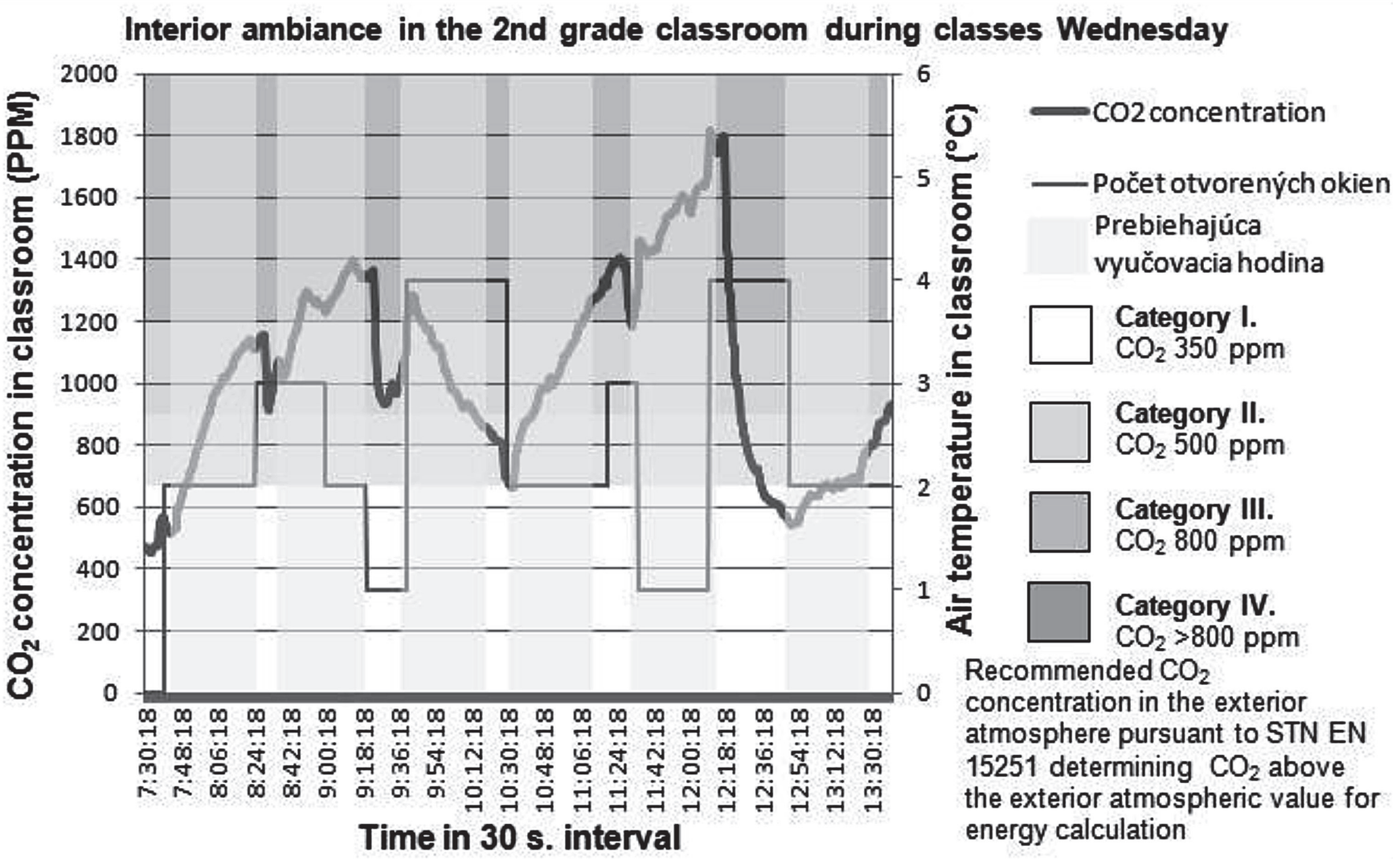

Fig. $6 \mathrm{CO}_{2}$ concentration, number of windows and duration of their opening during classes in the 2nd grade classroom (Javorček, M., 2016).

Air exchange in the 2nd grade classroom within 24 hours - Thursday - simulation

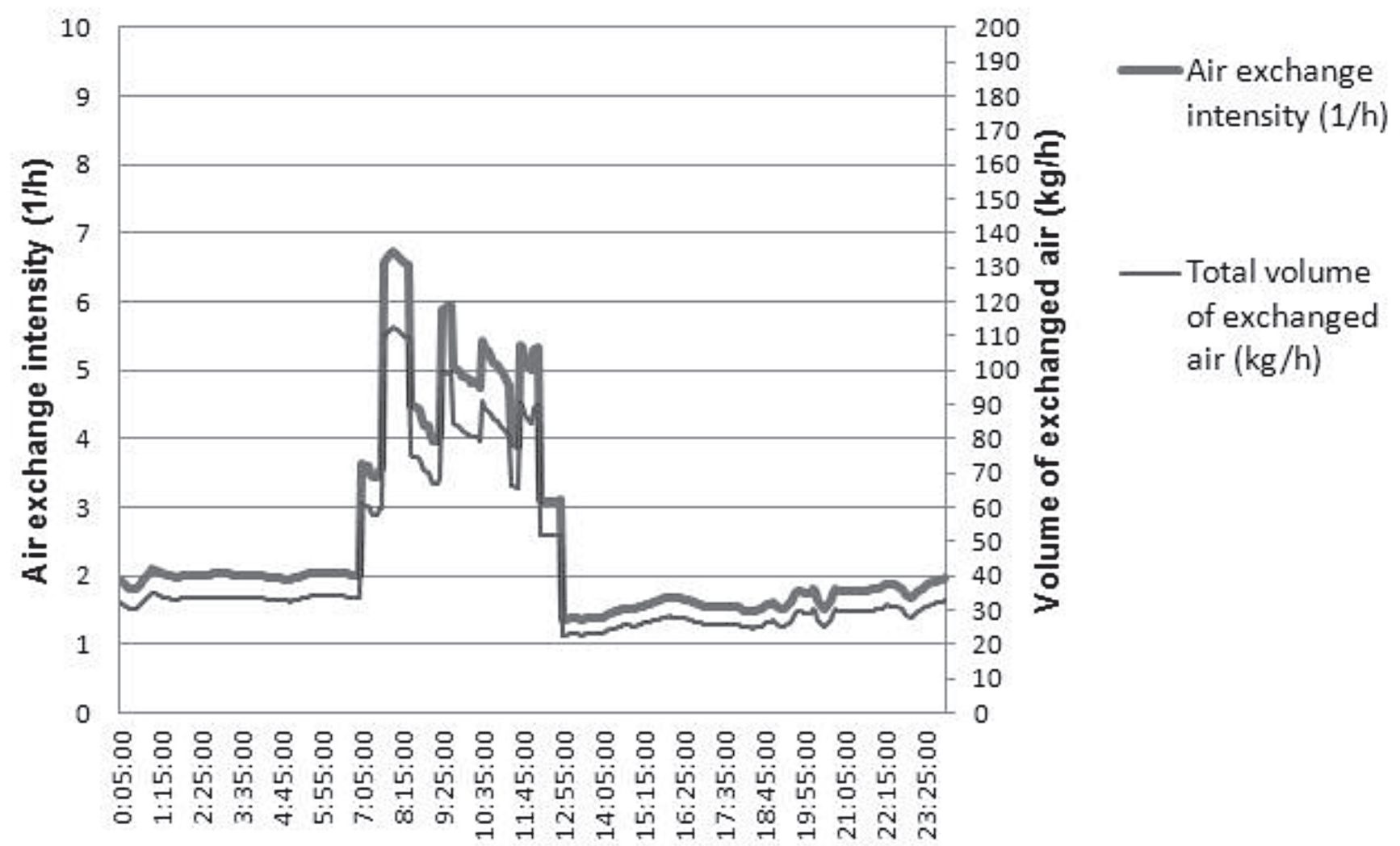

Fig. 7 Graphs of air exchange in the 2nd grade classroom - simulation results (Javorček, M., 2016). 


\section{CLASSROOM VENTILATION ANALYSIS}

We detected high window opening variability from the 2 nd grade classroom ventilation analysis. The fact resulting from personal cognition and the age of the students has been attributed to subjective evaluation of a lecturer who considered indoor environment parameters' quality during classes. The analysis outcomes proved the most balanced development of the monitored parameters during all days of measurement, and it indicates that opening of 3 windows ensures air exchange sufficient to ensure not increasing $\mathrm{CO}_{2}$ concentration but maintaining the value reported at the time. However, it is insufficient to ensure $\mathrm{CO}_{2}$ concentration drop below the limit value $1000 \mathrm{ppm}$, required by the standard. Opening of 4 windows ensures air exchange that resulted in decreasing $\mathrm{CO}_{2}$ concentration in the classroom. These findings apply only to the analyzed period.

Ventilation analysis provided us with the proof of changed average number of opened windows in particular classrooms during classes in particular classrooms. Average number of windows opened at the time of classes:

- 2 nd grade classroom $=2.65$

- 5 th grade classroom $=3.64$

- 8 th grade classroom $=3.42$

\section{DYNAMIC SIMULATION OF CLASSROOMS}

Computer model was developed in the software (SketchUp, 1999). It considers a selected classroom of typical dimensions. All analyzed classrooms were similar, with the same number of windows and the model was applied to all classrooms. The model variability referred to classroom engagement by students, $\mathrm{CO}_{2}$ production by students, and ventilation frequency. Climatic data entered in the software program (EnergyPlus simulation program) within the week of simulation were equal for each classroom, resulting from measured and analyzed data from the meteo-station installed in front of the classroom facade at the nearby playground in the distance approx. 50 $\mathrm{m}$ from the building front side.

We drew conclusions from the results obtained from parametric simulations on the typical model of a selected classroom at the elementary school, and thereby fulfilled the dissertation thesis goals. Parametric simulations were made for a typical classroom at Z $\breve{S}$ Strba with analyzed classroom engagement by students of various age, specified ventilation schedule, analyzed climatic data and classroom air permeability.

indoor environment condition in the classrooms was analyzed during Dec $10-16,2013$. Taking in account variation of the above-mentioned parameters, rate of the effects on classroom indoor environment quality was analyzed. A few observations were made on basis of evaluation of parameter situation outcomes:

- natural ventilation at air exchange intensity $3.5-4.01 / \mathrm{h}$ per a day during full classrooms helps maintain $20-24{ }^{\circ} \mathrm{C}$ interior air temperature in the analyzed zone in compliance with the Slovak Ministry of Healthcare Regulation No. 259/2008 Coll. at analyzed climatic data. Accumulation performance of building structures and interior heat accrual generated by people (students) significantly contributed to maintaining of interior temperature during intense natural ventilation with air exchange rate exceeding $4.51 / \mathrm{h}$;

- air permeability impact is not negligible either in case of the school building that had passed major reconstruction. As proved through the Blower door test performed pursuant to STN EN 13829 and also on basis of parametric situations outcomes, air exchange rate is not sufficient enough to avoid increase of $\mathrm{CO}_{2}$ concentration in the classroom on the following day, compared to exterior $\mathrm{CO}_{2}$ concentration. Measured $\mathrm{CO}_{2}$ concentration values were always below $1000 \mathrm{ppm}$, however with clearly detected $\mathrm{CO}_{2}$ concentration increase after turnout of the students in the classroom during the 1st classes. Therefore, the analyzed value cannot be considered sufficient. The first day of classes, Monday, was an exception of the measured values with analyzed $\mathrm{CO}_{2}$ concentration compared to average $380 \mathrm{ppm}$ $\mathrm{CO}_{2}$ concentration during the week. Average $\mathrm{CO}_{2}$ concentration increased on each following day of classes at the time of students' turnout in the classrooms. Air permeability $1.511 / \mathrm{h}$ was determined from in-situ measurements pursuant to the Blower door test. Based on parametric situations' outcomes, average air exchange rate at the time of empty classrooms and all windows closed referred to $1.83 \mathrm{1} / \mathrm{h}$;

- it results from the communication corridor environment condition analysis that the indoor environment quality, supported by the evaluated parameters, is significantly better than in all classrooms. These values were confirmed during the whole day of classes;

- air exchange was provided for by natural ventilation in all analyzed classrooms. Air exchange rate varied, depending on the number of opened windows in particular classrooms. Increasing trend of air exchange was detected from the parametric situations evaluation, depending on the students' age.

Average air exchange rate at the time of engaged classroom:

- 2nd grade classroom $\mathrm{n}=5,1 \mathrm{1} / \mathrm{h}$,

- 5th grade classroom $\mathrm{n}=5,61 / \mathrm{h}$,

- 8 th grade classroom $\mathrm{n}=6,21 / \mathrm{h}$.

- based on particular zones' parametric situations prepared in the SW program (EnergyPlus simulation program), it has been unambiguously proved that air exchange rate $\mathrm{n}=0,51 / \mathrm{h}$, considered in the energy efficiency calculations pursuant to STN 73 0540-2: 2012 is insufficient to ensure acceptable indoor environment in relation to $\mathrm{CO}_{2}$ concentration. The Slovak Ministry of Healthcare Regulation No. 259/2008 Coll. contains an example of thermal- humidity microclimate parameters for the premises with special requirements, with required exchange rate $n=3-81 / \mathrm{h}$ at school and pre-school facilities/ classrooms. Parametric situations outcomes also indicate insufficient air exchange rate $n=31 / \mathrm{h}$.

\section{SUMMARY}

Air exchange rate as a factor included in the elementary school buildings energy efficiency calculation has been determined pursuant to (STN 73 0540-2 2012). Calculation methods of building energy efficiency take in account air exchange rate in classrooms corresponding to at least $n=0,51 / \mathrm{h}$. This value is insufficient, as confirmed by in-situ measurements in all classrooms, and their subsequent analysis and application to parametric situations in SW EnergyPlus.

Requirement of air exchange variability was proved, depending on classroom engagement and $\mathrm{CO}_{2}$ concentration, as a major air quality indicator. Air exchange rate sufficient to ensure required indoor environment quality can be reached also by intense natural ventilation. This ventilation method is demanding for heat consumption at building heating mainly during winter season, which is contradictory to the heating energy requirement/ consumption reduction trend. 


\section{REFERENCES}

The Slovak Ministry of Healthcare Regulation No. 259/2008 Coll. dated June 18, 2008 on Details and Requirements of Interior Environment of Buildings, and on Minimum Requirements for Lower Standard Buildings and Accommodation Facilities.

STN EN 13829 (2001) Thermal - Technical Properties of BuildingsDetermination of Building Air Permeability. Ventilator Overpressure Method. SÚTN.

STN 73 0540-2 (2012) Thermal Protection of Buildings. Thermal-Technical Properties of Building Structures and Buildings. Part 2: Functional Requirements. SÚTN.

STN EN 15251 (2008): Entry Data on Interior Environment of Buildings for Design and Evaluation of Building Energy Efficiency - Air Quality, Thermal Condition of Ambiance, Lighting and Acoustics. SÚTN.
STN EN 15242 (2007) Ventilation of Buildings. Calculation Methods of Air Overflow in Buildings Including Infiltration. SÚTN.

SketchUp (1999) Last Software z Boulder, Colorado, Bradom Schellom a Joem Eschom.

EnergyPlus simulation program, US Department of Energy.

JAVORČEK, M. (2016) Analysis of Air Exchange Rate in Elementary School Classrooms. Bratislava: STU in Bratislava, Faculty of Civil Engineering. Dissertation Thesis. 